Bond University

Research Repository

\title{
Catheter-related thrombosis incidence and risk factors in adult cancer patients with central venous access devices
}

Ellis, Marc L; Okano, Satomi; McCann, Andrew; McDowall, Angela; Van Kuilenburg, Rosita; McCarthy, Alexandra L; Joubert, Warren; Harper, John; Jones, Mark; Mollee, Peter

Published in:

Internal Medicine Journal

DOI:

10.1111/imj.14780

Licence:

Other

Link to output in Bond University research repository.

Recommended citation(APA):

Ellis, M. L., Okano, S., McCann, A., McDowall, A., Van Kuilenburg, R., McCarthy, A. L., Joubert, W., Harper, J., Jones, M., \& Mollee, P. (2020). Catheter-related thrombosis incidence and risk factors in adult cancer patients with central venous access devices. Internal Medicine Journal, 50(12), 1475-1482.

https://doi.org/10.1111/imj.14780

\section{General rights}

Copyright and moral rights for the publications made accessible in the public portal are retained by the authors and/or other copyright owners and it is a condition of accessing publications that users recognise and abide by the legal requirements associated with these rights.

For more information, or if you believe that this document breaches copyright, please contact the Bond University research repository coordinator. 
Catheter-related thrombosis incidence and risk factors in adult cancer patients with central venous access devices

M. L. Ellis, ${ }^{\star} \dagger$ S. Okano, A. McCann,§ A. McDowall, ${ }^{\star}$ R. Van Kuilenburg, ${ }^{\star}$ A. L. McCarthy, ${ }^{\star}$ I W. Joubert, ${ }^{\star}$ J. Harper, ${ }^{\star \star}$ M. Jones, $\neq$ P. Mollee*†

* Division of Cancer Services, Princess Alexandra Hospital, Brisbane, Australia, † School of Medicine, University of Queensland, Brisbane, Australia, ¥ School of Public Health, University of Queensland, Brisbane, Australia, § Department of Vascular Medicine, Princess Alexandra Hospital, Brisbane, Australia, đI Faculty of Medical and Health Sciences, University of Auckland, Auckland, New Zealand, ** Department of Interventional Radiology, Princess Alexandra Hospital, Brisbane, Australia

Corresponding author:

Dr Marc Ellis, Division of Cancer Services, Princess Alexandra Hospital, Woolloongabba, QLD, Australia

ORCID: 0000-0002-2245-1668

Ph: +61 731762111

marc.ellis@hri.org.au

Running head: Catheter-related thrombosis in cancer through the copyediting, typesetting, pagination and proofreading process which may lead to differences between this version and the Version of Record. Please cite this article as doi: 10.1111/imj.14780 


\section{Purpose}

Central venous access devices (CVADs) are commonly employed in the management of cancer patients. While having several benefits they are associated with significant risks. We reviewed the incidence and risk factors for catheter-related thrombosis (CRT) in cancer patients with CVADs.

\section{Methods}

We performed a prospective observational cohort study of adult patients with cancer requiring a CVAD between January 12004 and June 29 2016. The rate of, and risk factors for the development of, symptomatic catheter-related thrombosis were evaluated.

\section{Results}

4920 central lines were inserted into 3130 patients. The incidence of CRT was $3.6 \%$. CRT developed a median of 12 days following line insertion. PICCs were associated with the highest rates of CRT (HR 22.2, 95\% Cl 2.9-170.6). Older age groups developed CRT at lower rates $(\mathrm{HR} 0.57 ; 95 \% \mathrm{Cl} 0.39-0.84$ for age $50-61$ years, and HR $0.63 ; 95 \% \mathrm{Cl} 0.45-0.89$ for age $>61$ years) compared to age $<50$ years. Increased CRT was seen in patients with prior CRT (HR 1.81; 95\% Cl 1.19-2.77). There was a trend to more for cancer subtype with a Khorana tumor score of 1 compared to those with a score of $0(\mathrm{HR} 1.37,95 \% \mathrm{Cl} 1.00-1.88)$. Hodgkin lymphoma, germ cell and oesophagus cancers had the highest CRT rates. Side of insertion was not associated with thrombosis risk (HR 0.77; 95\% Cl 0.57-1.05 $\mathrm{P}=0.10)$.

\section{Conclusions}

Age $<50$, PICC lines and prior CRT were associated with highest CRT rate. Cancer subtype and insertion side were not predictive of thrombosis. 


\section{Key Words}

Catheter, Cancer, Supportive Care, Thrombosis

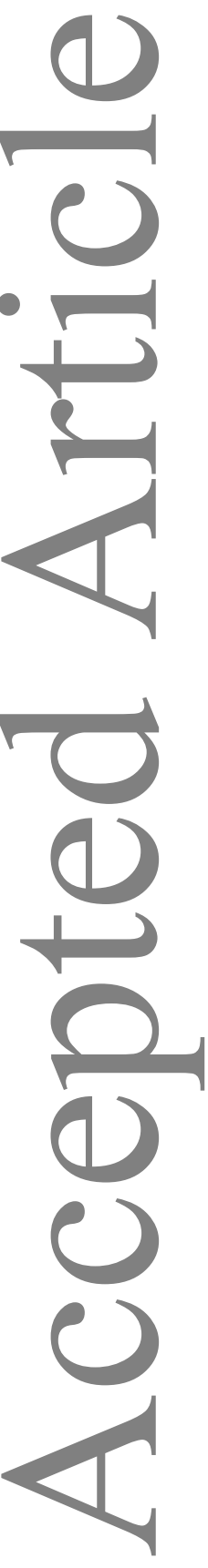




\section{Introduction}

Central venous access devices (CVADs) are commonly used in cancer patients for the administration of chemotherapy, parenteral nutrition, blood products and antibiotics as well as enabling frequent blood sampling without the need for venepuncture. They are also often utilised for the collection and infusion of stem cell transplants. CVADs, however, carry significant risks including mechanical, infective and thrombotic complications ${ }^{1}$. Peripherally inserted central catheters (PICCs) are rising in popularity because they are inserted in the arm and avoid many of the mechanical complications associated with traditional central venous catheters (CVCs). They also facilitate the transition from inpatient to outpatient therapy², can be inserted at the bedside by appropriately trained nurses and are associated with lower cost ${ }^{3}$. Despite this perceived benefit, PICCs have significantly higher rates of catheterrelated thrombosis (CRT) than their centrally inserted counterparts. The incidence of symptomatic CRT in cancer patients varies between studies with a reported incidence in meta-analysis of $6.67 \%$, with rates as low as $1.7 \%$ using long term skin tunnelled catheters $^{4,5}$. When screening techniques are used to detect asymptomatic thrombosis, a higher incidence has been reported ${ }^{6}$.

Aside from line type, several other risk factors for development of CRT have been evaluated. These include insertion site, catheter tip positioning, side of insertion, prior history of venous thrombosis, number of lumens, type of chemotherapy or prior 
catheter-associated blood stream infection $(\mathrm{CA}-\mathrm{BSI})^{5,7,8}$. This has led to the recommendation that PICCs be avoided, particularly in the critically ill or those with cancer or, if a PICC is required, avoidance of tip location in the upper superior vena cava and avoidance of insertion into the left $\mathrm{arm}^{9}$. The concern regarding left sided insertion is primarily based on data using centrally placed catheters, rather than PICCs. More recent data investigating PICC lines only generally do not support increased incidence with left sided PICCs ${ }^{2,5}$.

Certain types of cancer are associated with higher rates of venous thromboembolism which has led to the development and subsequent validation of risk scoring tools ${ }^{10}$ to determine the patients at highest risk of thrombotic events. The best validated is the Khorana score, which appraises the cancer subtype, body mass index and blood counts $^{11,12}$, with higher scores being associated with a higher risk of thrombosis. In the Khorana score gastric and pancreatic cancers have the highest risk of thrombosis. Whether the type of cancer influences CRT is uncertain.

We sought to review the incidence and risk factors for CRT in a large cohort of hematology and oncology patients in an Australian tertiary hospital.

\section{Methods}

Study setting and population 
This study was conducted in the Division of Cancer Services at the Princess Alexandra Hospital in Brisbane, Australia. This adult tertiary referral hospital includes medical oncology (excluding gynaecologic malignancy), haematology, radiation oncology and autologous but not allogeneic stem cell transplantation. All CVADs were inserted by trained operators within the Division of Radiology in a dedicated interventional facility using ultrasound guided venous puncture, as described elsewhere ${ }^{13}$. The study population comprised adult patients within the Division of Cancer Service, including hematology and oncology inpatients and outpatients, during the period 1 January 2004 to 26 June 2016. All PICCs were inserted into the arm, avoiding the antecubital fossa, while all tunnelled and non-tunnelled CVCs were inserted into the internal jugular vein.

Data were collected from the Division's CVAD database, where prospective data on all CVAD insertions are stored. The database captures the following variables: name, unique patient identifier, date of birth, age, gender, patient diagnosis, CVAD number, date inserted, CVAD type, number of lumens, purpose of CVAD, insertion site or location, reason for removal, number of days the CVAD was inserted, as well as other catheter-related complications (such as infection, thrombosis and line fracture). Patient demographics and date of CVAD insertion were downloaded into the Cancer Services CVAD database from the Interventional Radiology Department each week. Data for each CVAD episode were updated by nurses trained to enter relevant information when the CVAD was removed in the clinical area. Regular data quality checks were performed to update missing variables. In addition, the Department of Vascular Imaging was contacted for all ultrasound imaging showing thrombosis over 
the study period, which was cross-checked with the CVAD database to ensure all episodes of CRT were captured. The study was approved by the Metro South Human Research Ethics Committee.

Definitions

Catheter-related thrombosis was defined as thrombus occurring within the same vessel as a CVAD as detected using duplex ultrasonography, either while the CVAD was in situ or within one week of CVAD removal. No routine surveillance scanning was performed, thus imaging was performed on symptomatic patients only within either the diagnostic imaging department within the Division of Radiology or a dedicated vascular imaging suite within the Department of Vascular Medicine.

For the purposes of this study, hematologic malignancies were classified as 'intensive hematology' and 'other hematology' based on intensity of therapy. Intense regimens included those for the treatment of acute leukemias and high-grade lymphomas $(7+3$, HiDAC, FLAG, HyperCVAD) or autologous stem cell transplantation. Cancer types were assessed as very high, high or standard risk, based on the previously developed Khorana risk scoring system ${ }^{11,12}$, whereby patients with either gastric or pancreatic carcinoma were given a score of 2 , while lung, gynaecologic, and non-prostate genitourinary cancers or lymphomas were scored 1. Other malignancies were assigned a score of zero. When subsequently referred to in this paper, the term 
Khorana score refers specifically to the tumour subtype given to these various cancer subtypes as detailed in the Khorana risk scoring system.

\section{Statistical analysis}

The study population was reported with descriptive statistics. The unit of analysis was a central line within a patient and the primary outcome was the number of line days until development of a symptomatic catheter-related thrombus. In the cases where the lines were inserted and removed on the same days, its number of line day was defined as 0.5 day to account for the period of line insertion less than one day. Incidence probability curves were described using non-parametric estimates of cumulative incidence function (CIF) with competing risk model, where other reasons for line removal are considered to be competing risks.

Association between risk of CRT and patient or catheter related factors were examined using Cox regression model and competing risk model. As similar results were obtained from both models, Cox regression analysis results are presented. A multivariable model was fitted using all variables significant in the univariable analysis at the 20 percent level. The variables at the least significant level were sequentially excluded on the basis of Wald's statistics until all remaining variables in the model had $p$-values below 0.05 .

Subgroup analysis was performed for CRT on the patients with PICC lines. 
Robust covariance matrix was used to account for clustering of multiple lines within a patient. The proportional hazard assumption was checked for all variables included in the models. P-values were not adjusted for multiple testing. Analyses were performed using STATA 13.1 (StataCorp, TX).

\section{Results}

Baseline characteristics

A total of 4920 central lines were inserted into 3130 patients between January 1 , 2004 and June 29, 2016 and included in the analysis. The baseline characteristics of the study population and central venous catheters are summarised in Table 1 . The study population included cancer patients aged 15 to 92 years (median 56 years). 2068 (66.1\%) patients had a single line and 1062 (33.9\%) patients had multiple lines inserted over the course of treatment (range 2-10).

The majority of lines were PICCs (72.4\%) followed by non-tunnelled (12.9\%) and tunnelled central venous catheters (10.6\%) and implantable ports (4.1\%). The number of line days per inserted line ranged from $<1$ to 2551 days, with a median of 35 days. Median (IQR) line days for PICCs was 43 (20-88), tunnelled catheters 22 (15-36), non-tunnelled catheters 4 (2-7) and implantable ports 488 (192-1025). Fifty four percent of lines were inserted into the right side. Approximately half $(49.1 \%)$ the patients had a hematologic malignancy. The remainder were various solid tumours. The indication for line insertion was primarily administration of chemotherapy (78.1\%), followed by stem cell collection (10.8\%) and stem cell reinfusion $(6.7 \%)$. A 
total of $224(4.6 \%)$ lines were lost to follow up due to patient transfer to another facility.

A total of 177 (3.6\%) lines developed CRT. The rate of CRT per 1000-line days was 0.45. In the lines in which CRT developed, it did so at a median of 12 days (range 1266 days), with 75\% occurring within the first 26 days and 95\% occurring within 104 days of insertion (Figure 1). Lines were removed due to thrombosis in 145 (2.9\%) cases. 176 (99.4\%) of CRT events occurred in patients with PICCs, with only 1 event occurring in implantable port group and none in tunnelled $(n=521)$ or non-tunnelled $(n=634)$ CVADs.

\section{Analysis of CRT}

The results of univariable and multivariable Cox regression analyses of CRT are provided in Table 2. In multivariable analysis patients with PICC lines had the greatest risk of CRT with the hazard rate 22.2 times $(95 \% \mathrm{Cl} 12.9-170.6)$ higher than implanted ports. There were no episodes of CRT associated with tunnelled or non-tunnelled centrally-inserted lines. Older age groups (50-61 years old and > 61 years old) developed CRT at lower rates (HR 0.57, 95\%Cl 0.39-0.84 and HR 0.63, 95\% Cl: 0.450.89 respectively) compared to the youngest age group (<50 years old). When age (years) was fitted into the model in place of age group, there was trend that the hazard rate reduced with an increase in patient's age $(\mathrm{HR} 0.99,95 \% \mathrm{Cl} 0.91-1.00, \mathrm{p}=0.031)$. There was also evidence that greater number of prior CRT was associated with increased risk of CRT (HR 1.81, 95\% Cl 1.19-2.77, p=0.006, Figures 2 a-c). 
The tumour subtype (defined by Khorana score) was not identified as a potential predictor of CRT. However, patients with Khorana tumour score of 1 had an increased risk of CRT compared to those with Khorana tumour score of 0 when controlling for line type, prior CRT and age group (HR 1.37, 95\% Cl: 1.00-1.88) (Figure 2d). A further descriptive analysis of CRT incidence across different cancer subtypes showed that patients with germ cell tumours and Hodgkin lymphoma (Khorana score 1) had higher rates of CRT (1.81 and 0.9 per 1000 line days respectively) (Table 3). Oesophageal carcinoma (Khorana score 0) also had a higher rate of CRT, 1.21 per 1000-line days while myeloma had the lowest rate (no events).

Number of lumens, side of insertion and gender were found to be confounded by line type and not found to be significantly associated with risk of CRT in multivariable analysis. There was no difference in incidence rates of CRT between lymphoid and myeloid hematologic malignancies relative to solid tumours (HR 0.95; 95\% Cl 0.671.34, HR 0.77; 95\% Cl 0.45-1.34 respectively; $\mathrm{P}=0.66)$.

Secondary analysis of CRT in PICC lines

We repeated the analysis specifically investigating PICC lines. A total of $3564(72.2 \%)$ lines were inserted. The median line insertion duration was 43 (IQR 20-88) days with a thrombosis rate $4.9 \%$ ( 0.75 per 1000 -line days). Age $<50$ and number of prior CRT events remained statistically significant predictors of CRT. There was no evidence of association between risk of CRT and insertion side, Khorana tumour score, gender or disease category. 
When the analysis was also performed using the competing risk model, features found to be significant in the Cox analyses retained their significance (data not shown).

\section{Discussion}

CRT is a not infrequent occurrence in patients with cancer. In our study of almost 5000 lines in 3130 patients, CRT incidence was 3.6\%. In a meta-analysis of over 25000 patients, the rate of CRT within the subgroup of 3430 cancer patients was $6.67 \%{ }^{5}$. Our observed lower incidence may be due, in part to our method of insertion, with all being inserted using ultrasound guided insertion and fluoroscopic confirmation of tip location in a dedicated interventional radiology facility. Similar to these studies, we also employed imaging of symptomatic patients, rather than routine screening. Our data are also consistent with the published literature in that, when compared to other CVADs, we found the highest incidence of CRT related to PICCs, where the overall incidence of CRT was $4.9 \%$.

The literature is conflicting with regard to insertion side and risk of thrombosis. In accordance with the international guidelines published by Debourdeau et $\mathrm{al}^{14}$, avoidance of the left side is suggested, based on evidence from old studies using only centrally inserted CVADs ${ }^{15-17}$. The results of our large study are consistent with other reports which investigated CRT with PICCs and demonstrated no significant difference based on laterality of insertion $6,8,18,19$. Thus, it appears reasonable to conclude that with respect to PICC lines, the side of insertion is not important. We were unable to 
investigate the influence of laterality of insertion on centrally inserted lines as only 2 patients developed CRT outside of the PICC group (0.14\%).

The median duration of line days for tunnelled lines and PICC lines was 22 (IQR 1536) and 43 (IQR 20-88) days respectively, both longer than the median time to development of CRT of 12 (IQR 7-26) days. Implantable ports remained in situ for a median of 488 (IQR 192-1025) days. With all but one CRT event occurring in patients with PICCs, clearly the risk of CRT is relatively unique to PICC lines. The reasons for such a low incidence in the internal jugular route most likely relate to a combination of factors, including a much shorter intravascular course, larger luminal diameter of the punctured vein and universal insertion in an interventional radiology facility plus fluoroscopic confirmation of tip location. The lack of CRT events in the non-tunnelled group is most likely due to small numbers of line days (median 4, IQR 2-7 days) as these lines are primarily used for stem cell collection, infusion or haemodialysis in our institution.

Increased rates of CRT have been seen in patients with a history of $\mathrm{DVT}^{8,19}$. Although our database did not record this information, it demonstrated a trend toward an increased rate of CRT in those patients with a previous CRT episode. We also evaluated the influence of the previously described Khorana scoring system ${ }^{11}$. Our data showed no evidence of a significant association specifically between the tumour score and the CRT rate. There was a trend that patients with a Khorana score of 1 had higher risk than those with a Khorana score of 0 (HR 1.37, 95\% Cl: 1.00-1.88). It should be noted that we did not consider other factors (e.g. BMI, haemoglobin level) 
in the original Khorana model, and that the Khorana model was designed for assessment of overall VTE risk in cancer patients rather than CRT, or within specific tumour subtypes. Additionally, recent studies in specific types of cancer have called into question the discriminatory power of this model $20,21$.

In our study the rate of CRT was the highest in patients receiving treatment for germ cell tumours. High rates of VTE have previously been reported in these patients, with up to $40 \%$ of patients having a deep venous thrombosis ${ }^{22}$ while receiving platinumbased therapy. A previous meta-analysis concluded that brain and pancreas tumours have the highest risk of $\mathrm{VTE}^{23}$. There were very few brain tumour patients in our dataset, most likely reflecting the lack of necessity for long-term intravenous access in this patient group.

In the broader context of all CRT (not specific to cancer), a systematic review by Leung and colleagues reported a weak influence of patient age, with only 3 of 17 reviewed studies showing an association. These studies all demonstrated older age having a positive association with $\mathrm{CRT}^{24}$. Older patients are more likely to have comorbid illnesses which require anticoagulant or antiplatelet agents. It has been demonstrated in numerous randomised controlled trials that prophylaxis with low molecular weight heparin, fixed or variable dose warfarin do not protect from development of symptomatic CRT in cancer patients ${ }^{25}$, suggesting baseline anticoagulation is unlikely the explanation. The role of novel oral anticoagulant agents and antiplatelet drugs in CRT prevention is less clear and warrants further prospective exploration. Interestingly, our data indicate that patient age may be a potential predictor of CRT, 
with the highest incidence in patients under the age of 50 . The reasons for an increase in CRT in younger patients at our centre are unclear but may be related to different cancer types seen in these patients. Further studies are needed to elucidate the association between young age and the risk of CRT.

One weakness of this study relates to the reporting of CRT, being limited to those detected in our institution. Patients who had imaging performed externally might not have been detected in this study, however we feel the impact of this is likely to be small, based on the way patients are followed up and encouraged to return to the treating hospital if there are problems or concerns. Based on this, the overall incidence of CRT could be under-reported in these data. There is also a risk of confounding as certain line types are more likely to be inserted into patients with specific malignancies. While residual confounding cannot be completely accounted for, we have attempted to minimise this risk through using a multivariate analysis. When we looked specifically at AML patients (due to the large numbers of tunnelled CVL and PICC lines), CRT was demonstrated exclusively within those with PICCs.

This study does have several strengths. The central line data were collected prospectively into a purpose-built database. To our knowledge, this is the largest published single-centre study assessing the risk of CRT among patients with cancer, across all types of lines. In addition, this is the first attempt to investigate the rates of CRT in patients with different cancer subtypes. 
The decision about what form of CVAD to use in the cancer patient is a complex one. PICCs are a popular choice based primarily on convenience, cost and ease of access. The decision to insert a PICC must include consideration of the higher risk of thrombosis, particularly in those who have experienced CRT previously, younger patients or those with higher risk cancers.

In conclusion, we have identified that in patients with cancer PICC lines are associated with the highest risk of CRT. CRT is extremely uncommon in centrally inserted tunnelled and non-tunnelled lines when internal jugular access is utilised under ultrasound guidance in a dedicated interventional radiology facility. Patients are at increased risk of CRT if they are aged $<50$ years or have a prior history of thrombosis however tumour risk based on those in the Khorana model and insertion side were not significant predictors of thrombosis. 
1. Gonzalez G, Davidoff AM, Howard SC, Pui CH, Rao BN, Shenep JL, et al. Safety of central venous catheter placement at diagnosis of acute lymphoblastic leukemia in children. Pediatr Blood Cancer. 2012;58(4):498-502.

2. Chopra V, Ratz D, Kuhn L, Lopus T, Lee A, Krein S. Peripherally inserted central catheterrelated deep vein thrombosis: contemporary patterns and predictors. J Thromb Haemost. 2014;12(6):847-54.

3. Cheong K, Perry D, Karapetis C, Koczwara B. High rates of complications associated with peripherally inserted central venous catheters in patients with solid tumours. Internal Med J. 2004;34(5):234-8.

4. Sriskandarajah P, Webb K, Chisholm D, Raobaikady R, Davis K, Pepper N, et al. Retrospective cohort analysis comparing the incidence of deep vein thromboses between peripherally-inserted and long-term skin tunneled venous catheters in hemato-oncology patients. Thromb J. 2015;13:21. 5. Chopra V, Anand S, Hickner A, Buist M, Rogers MA, Saint S, et al. Risk of venous thromboembolism associated with peripherally inserted central catheters: a systematic review and meta-analysis. Lancet. 2013;382(9889):311-25.

6. Abdullah JJ, Mohammad N, Sangkar JV, Aziz YFA, Gan GG, Goh KY, et al. Incidence of upper limb venous thrombosis associated with peripherally inserted central catheters (PICC). Br J Radiol. 2005;78(931):596-600.

7. Luciani A, Clement O, Halimi P, Goudot D, Portier F, Bassot V, et al. Catheter-related upper extremity deep venous thrombosis in cancer patients: a prospective study based on Doppler US. Radiology. 2001;220(3):655-60.

8. Saber W, Moua T, Williams EC, Verso M, Agnelli G, Couban S, et al. Risk factors for catheterrelated thrombosis (CRT) in cancer patients: a patient-level data (IPD) meta-analysis of clinical trials and prospective studies. J Thromb Haemost. 2011;9(2):312-9.

9. $\quad$ Prandoni P. Peripherally inserted catheters: all that glitters is not gold. Lancet. 2013;382(9889):288-90.

10. Thaler J, Ay C, Pabinger I. Venous thromboembolism in cancer patients - risk scores and recent randomised controlled trials. Thromb Haemost. 2012;108(6):1042-8.

11. Khorana AA, Kuderer NM, Culakova E, Lyman GH, Francis CW. Development and validation of a predictive model for chemotherapy-associated thrombosis. Blood. 2008;111(10):4902-7.

12. Dutia M, White RH, Wun T. Risk assessment models for cancer-associated venous thromboembolism. Cancer. 2012;118(14):3468-76.

13. Mollee $\mathrm{P}$, Jones $\mathrm{M}$, Stackelroth J, van Kuilenburg R, Joubert W, Faoagali J, et al. Catheterassociated bloodstream infection incidence and risk factors in adults with cancer: a prospective cohort study. J Hosp Infect. 2011;78(1):26-30.

14. Debourdeau P, Farge D, Beckers M, Baglin C, Bauersachs RM, Brenner B, et al. International clinical practice guidelines for the treatment and prophylaxis of thrombosis associated with central venous catheters in patients with cancer. J Thromb Haemost. 2013;11(1):71-80.

15. Craft PS, May J, Dorigo A, Hoy C, Plant A. Hickman catheters: left-sided insertion, male gender, and obesity are associated with an increased risk of complications. Aust NZ J Med. 1996;26(1):33-9.

16. Cadman A, Lawrance JAL, Fitzsimmons L, Spencer-Shaw A, Swindell R. To clot or not to clot? That is the question in central venous catheters. Clin Radiol. 2004;59(4):149-355.

17. Verso M, Agnelli G. Venous thromboembolism associated with long-term use of central venous catheters in cancer patients. Journal of Clinical Oncology. 2003;21(19):3665-75. 
18. Sperry BW, Roskos M, Oskoui R. The effect of laterality on venous thromboembolism. J Vasc Access. 2012;13(1):91.

19. Lobo BL, Vaidean G, Broyles J, Reaves AB, Shorr RI. Risk of venous thromboembolism in hospitalized patients with peripherally inserted central catheters. J Hosp Med. 2009;4(7):417-22.

20. Chaudhary A, Balakrishnan A, Thai C, Holmstrom B, Nanjappa S, Zhenjun M, et al. Validation of the Khorana score in a large cohort of cancer patients with venous thromboembolism. Blood. 2016;128(22):879.

21. Mansfield AS, Tafur AJ, Wang CE, Kourelis TV, Wysokinsa EM, Yang P. Predictors of active cancer thromboembolic outcomes: validation of the Khorana score among patients with lung cancer. J Thromb Haemost. 2016;14(9):1773-8.

22. Solari L, Kronig M, Ihorst G, Drognitz K, Heinz J, Jilg CA, et al. High Rates of Thromboembolic Events in Patients with Germ Cell Cancer Undergoing Cisplatin-Based Polychemotherapy. Urol Int. 2016;96(4):399-405.

23. Horsted F, West J, Grainge MJ. Risk of venous thromboembolism in patients with cancer: a systematic review and meta-analysis. PLoS Med. 2012;9(7):e1001275.

24. Leung A, Heal C, Perera M, Pretorius C. A systematic review of patient-related risk factors for catheter-related thrombosis. J Thromb Thrombolysis. 2015;40(3):363-73.

25. Lee AY, Kamphuisen PW. Epidemiology and prevention of catheter-related thrombosis in patients with cancer. J Thromb Haemost. 2012;10(8):1491-9. 


\section{Figure Legend}

Figure 1. Cumulative probability of catheter-related thrombosis estimated by competing risks model. Solid lines represent cumulative incidence function. Hatched lines represent 95\% confidence interval.

Figure 2. Cumulative probability of catheter-related thrombosis according to; a) line type; b) patient age group; c) presence of prior thrombosis; d) Khorana risk score (2 = pancreas, stomach, 1= lung, lymphoma, genitourinary (excluding prostate), gynaecologic, $0=$ all other cancers) . 
Table 1. Baseline Characteristics

\begin{tabular}{|c|c|}
\hline Variables & Total $(n=4920)$ \\
\hline Age (years), median (IQR) & $56(46-65)$ \\
\hline \multicolumn{2}{|l|}{ Gender } \\
\hline Female & $2158(43.9 \%)$ \\
\hline Male & 2762 (56.1\%) \\
\hline \multicolumn{2}{|l|}{ No. of prior lines } \\
\hline 0 & 3130 (63.6\%) \\
\hline 1 & $1062(21.6 \%)$ \\
\hline 2 & $430(8.7 \%)$ \\
\hline$\geq 3$ & $398(6.1 \%)$ \\
\hline \multicolumn{2}{|l|}{ No. of prior CRT } \\
\hline 0 & $4741(96.4 \%)$ \\
\hline 1 & $167(3.4 \%)$ \\
\hline 2 & $11(0.2 \%)$ \\
\hline 3 & $1(<0.1 \%)$ \\
\hline \multicolumn{2}{|l|}{ Line type } \\
\hline Tunnelled (Hickman) & $470(9.6 \%)$ \\
\hline Tunnelled (Apheresis Hickman) & $51(1.0)$ \\
\hline Non-tunnelled (Medcomp) & $634(12.9 \%)$ \\
\hline PICC & $3564(72.4 \%)$ \\
\hline Implantable port (Port-a-cath) & $201(4.1 \%)$ \\
\hline \multicolumn{2}{|l|}{ Side of insertion } \\
\hline Left & $2267(46.1 \%)$ \\
\hline Right & $2653(53.9 \%)$ \\
\hline \multicolumn{2}{|l|}{ Insertion site } \\
\hline Jugular & $1320(26.8 \%)$ \\
\hline Arm & $3576(72.7 \%)$ \\
\hline Femoral & $24(0.5 \%)$ \\
\hline \multicolumn{2}{|l|}{ Lumens } \\
\hline Single & $243(4.9 \%)$ \\
\hline Double & $4660(94.7 \%)$ \\
\hline Triple & $17(0.3 \%)$ \\
\hline \multirow{2}{*}{\multicolumn{2}{|c|}{$\begin{array}{l}\text { Patient Diagnosis: } \\
\text { Risk groups (Khorana tumour score) } \\
\text { ( } n=4908)\end{array}$}} \\
\hline & \\
\hline 0 & $3297(67.2 \%)$ \\
\hline 1 & $1411(28.7 \%)$ \\
\hline 2 & $200(4.1 \%)$ \\
\hline \multicolumn{2}{|l|}{ Treatment regimen } \\
\hline Intensive haematology & $2197(44.7 \%)$ \\
\hline Other haematology & $217(44.4 \%)$ \\
\hline Other cancers & $2506(50.9 \%)$ \\
\hline \multicolumn{2}{|l|}{ Patient Diagnosis } \\
\hline Myeloid malignancies & $601(12.2 \%)$ \\
\hline Lymphoid malignancies & $1813(36.8 \%)$ \\
\hline Other cancers & $2506(50.9 \%)$ \\
\hline
\end{tabular}




\begin{tabular}{ll}
\hline Purpose of line insertion & \\
Chemotherapy & $3893(77.2)$ \\
Blood Products & $24(0.5)$ \\
IV antibiotics & $193(3.8)$ \\
Stem Cell Collection & $534(10.6)$ \\
Stem Cell Transplant & $328(6.5)$ \\
Therapeutic Apheresis & $45(0.9)$ \\
Dialysis & $26(0.5)$ \\
\hline
\end{tabular}

CRT, catheter-related thrombosis; PICC, peripherally inserted central venous catheter; IQR, Interquartile range 
Table 2. Cox regression analysis of cancer-related thrombosis.

\begin{tabular}{|c|c|c|c|c|}
\hline & \multicolumn{2}{|l|}{ Univariable Analysis } & \multicolumn{2}{|c|}{ Multivariable analysis } \\
\hline & $\mathrm{HR}(95 \% \mathrm{Cl})$ & p-value & $\mathrm{HR}(95 \% \mathrm{Cl})$ & $p$-value \\
\hline Age & $0.99(0.99-1.00)$ & 0.22 & & \\
\hline Age group & & 0.027 & & 0.005 \\
\hline$<50$ & 1.00 & & 1.00 & \\
\hline $50-61$ & $0.59(0.40-0.88)$ & & $0.57(0.39-0.84)$ & \\
\hline$>61$ & $0.72(0.50-1.02)$ & & $0.63(0.45-0.89)$ & \\
\hline Gender & & 0.076 & & \\
\hline Female & 1.00 & & & \\
\hline Male & $1.34(0.97-1.85)$ & & & \\
\hline No. of prior line & $0.90(0.76-1.08)$ & 0.26 & & \\
\hline No. of prior CRT & $1.94(1.29-2.91)$ & 0.001 & $1.81(1.19-2.77)$ & 0.006 \\
\hline Line type & & 0.004 & & 0.003 \\
\hline Tunnelled & $0.00 *$ & & 0.00 * & \\
\hline Non-tunnelled & $0.00 *$ & & $0.00 *$ & \\
\hline PICC & $20.43(2.67-156.50)$ & & $22.2(2.9-170.6)$ & \\
\hline Implantable port & 1.00 & & 1.00 & \\
\hline Side of insertion & & 0.10 & & \\
\hline Left & 1.00 & & & \\
\hline Right & $0.77(0.57-1.05)$ & & & \\
\hline Lumens & & 0.035 & & \\
\hline Single & 1.00 & & & \\
\hline Multiple & $2.69(1.07-6.77)$ & & & \\
\hline Khorana tumour score & & 0.063 & & \\
\hline 0 & 1.00 & & & \\
\hline 1 & $1.47(1.06-2.05)$ & & & \\
\hline 2 & $0.95(0.44-2.05)$ & & & \\
\hline Treatment regimen & & 0.26 & & \\
\hline Intensive hematology & $0.84(0.60-1.17)$ & & & \\
\hline Other hematology & $1.43(0.73-2.80)$ & & & \\
\hline Other cancers & 1.00 & & & \\
\hline Patient diagnosis & & 0.66 & & \\
\hline Myeloid malignancies & $0.77(0.45-1.34)$ & & & \\
\hline
\end{tabular}




\begin{tabular}{ll}
\hline Lymphoid malignancies & $0.95(0.67-1.34)$ \\
Other cancers & 1.00 \\
\hline * 95\% Cl was not determined due to no events in the categories.
\end{tabular}

* $95 \% \mathrm{Cl}$ was not determined due to no events in the categories.

CRT, catheter-related thrombosis; PICC, peripherally inserted central venous catheter; 
Table 3. CRT rates (percentage and events per 1000 line-days) by cancer subtypes

\begin{tabular}{lll}
\hline Cancer subtype & $\begin{array}{l}\text { \% (No. CRT/No. } \\
\text { catheter) }\end{array}$ & $\begin{array}{l}\text { CRT events per } \\
\mathbf{1 0 0 0} \text { line days }\end{array}$ \\
\hline AML & $3.0 \%(14 / 472)$ & 0.61 \\
APML & $3.2 \%(3 / 93)$ & 0.61 \\
ALL & $3.7 \%(5 / 137)$ & 0.54 \\
NHL & $3.6 \%(36 / 1002)$ & 0.69 \\
Myeloma & $0 \%(0 / 457)$ & 0 \\
Breast & $4.4 \%(19 / 430)$ & 0.17 \\
Colon/Rectal & $3.9 \%(32 / 819)$ & 0.42 \\
Gastric & $4.4 \%(6 / 136)$ & 0.57 \\
Sarcoma & $1.7 \%(2 / 120)$ & 0.14 \\
Lung & $3.6 \%(5 / 141)$ & 0.29 \\
Oesophagus & $6.0 \%(23 / 384)$ & 1.21 \\
Pancreas & $1.6 \%(1 / 64)$ & 0.20 \\
Hodgkin Lymphoma & $6.3 \%(9 / 142)$ & 0.90 \\
Germ cell & $6.1 \%(7 / 115)$ & 1.81 \\
Others & $3.7 \%(15 / 408)$ & 0.65 \\
Total & $3.6 \%(177 / 4920)$ & 0.45
\end{tabular}

AML, Acute myeloid leukemia; APML, Acute promyelocytic leukemia; ALL, Acute lymphoblastic leukemia; NHL, non-Hodgkins lymphoma; CRT, catheter-related thrombosis 


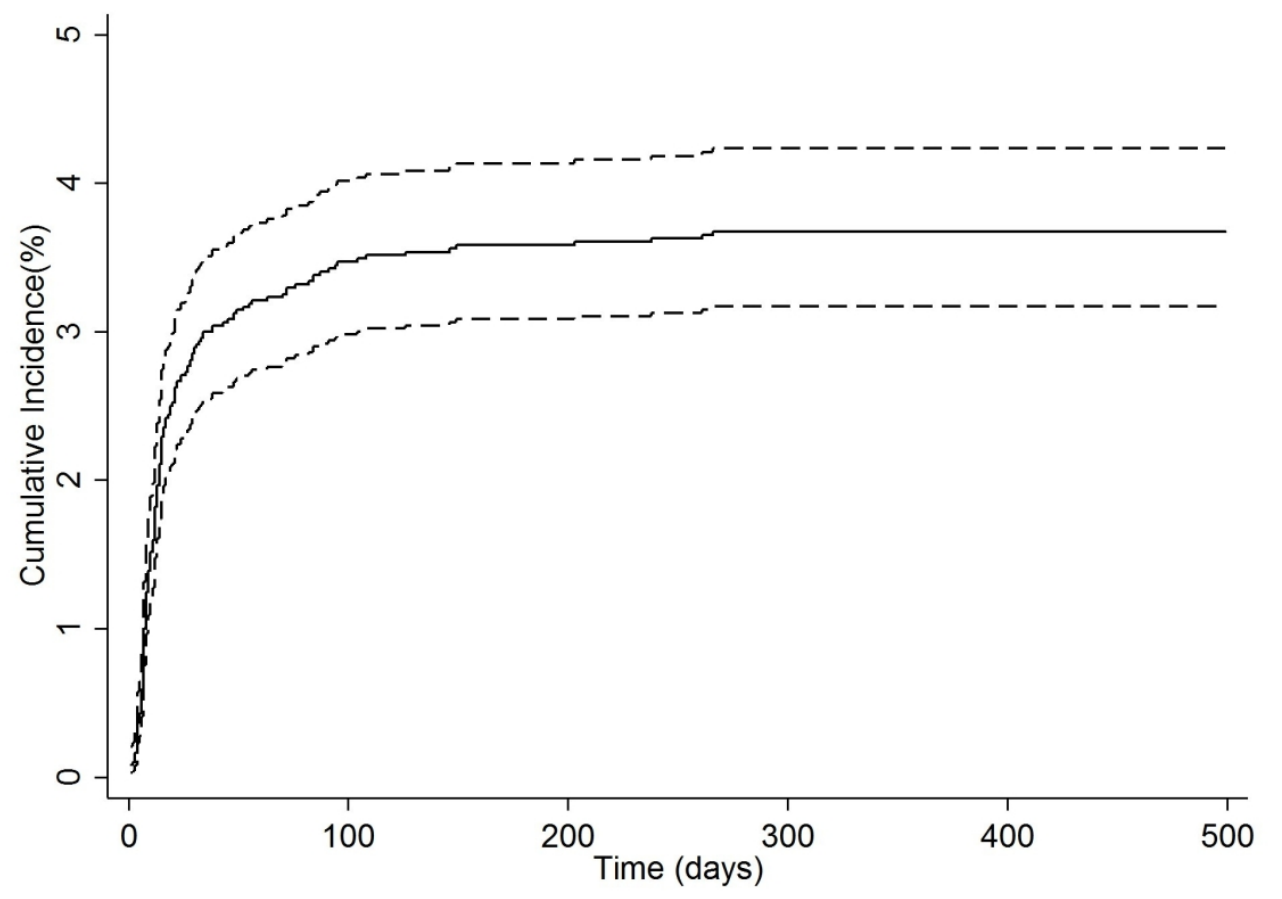

This article is protected by copyright. All rights reserved. 
(a)

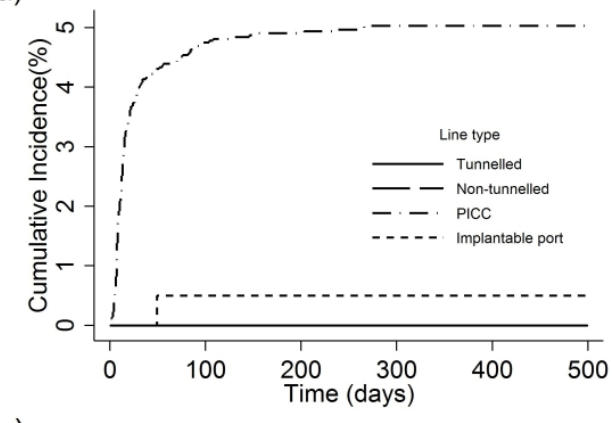

(c)

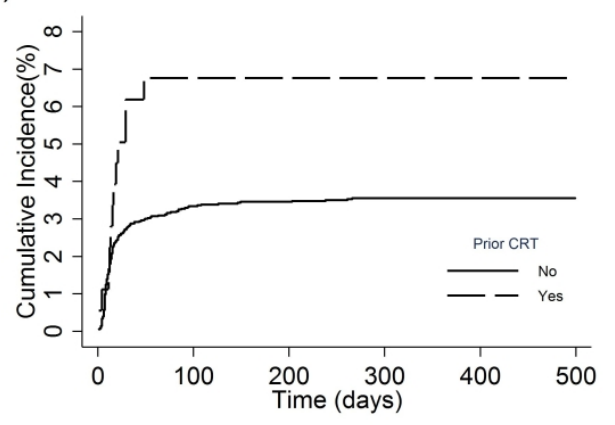

(b)

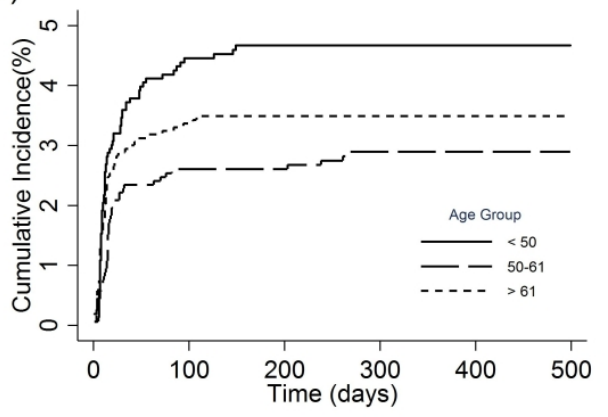

(d)

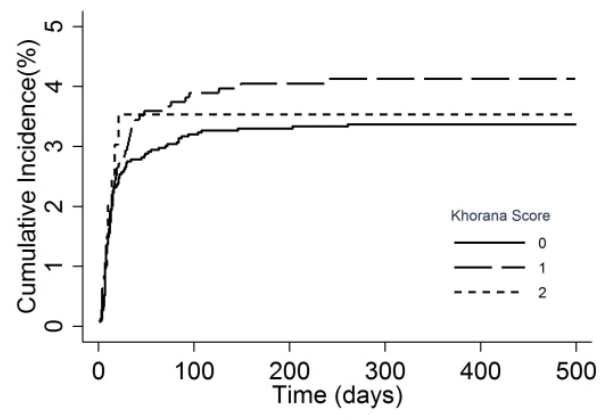

